phenomenological studies of psychoses, among others. Intervention studies are rare and cohort studies few. Research addressing special groups such as children and the elderly is very much in its infancy.

\section{Mental health policy}

The first mental health policy for the country was launched in 1991 (Federal Ministry of H ealth, 1991). Its laudable 14 declarations include:

The Association of Psychiatrists in Nigeria, formed in 1969 at a meeting in Ibadan attended by seven members, has grown such that there are now over 130 members and associate members. Its annual general and scientific meeting has become an established annual event.
The mental health policy shall be based on the national philosophy of social justice and equity.

Individuals with mental, neurological and psychological disorders shall have the same rights to treatment and support as those with physical illness and shall be treated in health facilities as close as possible to their own community. $\mathrm{N}$ o person shall suffer discrimination on account of mental illness.

It also recommends a revision of laws relating to the mentally ill in $\mathrm{N}$ igerian statutes. The policy is backed with a $\mathrm{N}$ ational Mental $\mathrm{H}$ ealth Programme and Action Plan, which, unfortunately, has hardly been implemented.

The legal provisions in the $\mathrm{N}$ igerian statutes are obsolete. For example, the country still operates within the framework of the Lunacy Act Cap. 112 (Cap. 81 Lagos) of 1916, which in turn was based on the Lunacy Acts 1890-1908 of the U nited Kingdom. Accordingly, the Act recommends certification for 'lunatics', including 'an idiot or any person of unso und mind'. These provisions fail to recognise the present-day view of severe mental disorders as treatable conditions, or to give special consideration for actions that breach the laws of the land but that are committed when the individual is unable to make a reasoned judgement. However, there is some hope that, in the new democratic political dispensation, there may be some positive changes, as attempts at revising these laws are currently under way.

\section{Professional groups}

The Association of Psychiatrists in N igeria, formed in 1969 at a meeting in Ibadan attended by seven members, has grown such that there are now over 130 members and associate members. Its annual general and scientific meeting has become an established annual event. The Association was a strong member of the now defunct African Psychiatric Association. Several of its members were also instrumental in the formation and nurturing of the African Journal of Psychiatry, which, unfortunately, is also now defunct. Indeed, the involvement of $\mathrm{N}$ igerian psychiatrists in international professional associations started with the organisation in 1961 of the first PanAfrican Psychiatric Conference by Dr Lambo. Participants at the conference had come from several African countries, as well as Europe and N orth America. Currently, $\mathrm{N}$ igerian psychiatrists are fully involved in the activities of the World Psychiatric Association and newly established Asso ciation of African Psychiatrists and Allied Workers.

Several $\mathrm{N}$ igerian psychiatrists are members or fellows of the Royal College of Psychiatrists. At present, there is no organised forum for them in which to meet and deliberate on College affairs, even though $\mathrm{N}$ igerian members and fellows are often present at the annual College conference. The story is different for $\mathrm{N}$ igerian psychiatrists working in the UK. Several of these have played active roles in the activities of the College and some have held important leadership positions in training and examination programmes.

\section{References}

Anumonye, A. (1976) Nigerian Mental Health Directory. Lagos: LUTH/C ollege of Medicine of the U niversity of Lagos Press.

Asuni, T. (1967) Aro Mental Hospital in perspective. American Journal of Psychiatry, 124, 763-770.

Asuni, T. (1972) Psychiatry in N igeria over the years. Nigerian Medical Journal, 2, 54-58.

Federal Ministry of Health (1991) The National Mental Health Policy in N igeria. Lagos: Federal Ministry of Health.

Jegede, R. O. (1981) N igerian psychiatry in perspective. Acta Psychiatrica Scandinavica, 63, 45-56.

Leighton, A. H., Lambo, T. A., Hughes, C. C., et al (1963) Psychiatric Disorder Among the Yoruba - A Report from the Cornell-Aro Mental Health Research Project in the Western Region, Nigeria. Ithaca, NY: Cornell U niversity Press.

World Health O rganization (2000) The World Health Report 2000. Geneva: WHO

World Health O rganization (2001) Atlas: Country Profile of Mental Health Resources. Geneva: WHO.

\title{
Psychiatric services in Egypt - an update
}

\section{Ramy Daoud ${ }^{1}$, Sherif Atallah² and Nasser Loza ${ }^{3}$}

\author{
${ }^{1}$ Resident in Psychiatry, Behman Hospital, Cairo \\ ${ }^{2}$ Consultant Psychiatrist and Medical Director, Behman Hospital, Cairo \\ ${ }^{3}$ Consultant Psychiatrist and Director, Behman Hospital, 32 Marsad Street, Cairo 11421, Egypt, \\ email nloza@behman.com
}

or over a thousand years, the Hippocratic

system of medicine prevailed in Europe. It went into oblivion during the Dark Ages, when there

was a reversion to the demoniacal theories of mental illness. H ippocrates' works survived, however, in the library at Alexandria, where they were 
translated into Arabic. These and other classical works were retranslated into Latin and G reek from the 12th century on, ushering in the Renaissance.

Around 1284 CE, the Sultan of Egypt, Al Mansour Kalawo on, bequeathed one of his palaces in $C$ airo for the construction of a general hospital with a department of psychiatry. It soon became one of the most famous hospitals throughout the Islamic world. It was, and still is, known as Dar Al Shefa, literally the House of Healing (O kasha et al, 1993). Two features were remarkable for that era: the care of mental patients in a general hospital, and the involvement of the community in the welfare of the patients, which foreshadowed modern trends by six centuries (Baasher, 1975).

The mentally disturbed usually received baths, fomentation, compresses, bandaging and massage with various oils. Blood-letting, cupping and cautery were also widely used. A familiar term for an antidepressant in the medieval period was mufarrih an-nafs, 'gladdening of the spirit'. Those suffering from insomnia would be placed in a separate hall to listen to harmonious music and to hear skilled story-tellers recite their tales (Buergel, 1975; D ols, 1992).

\section{Mental health resources}

Today, the population of Egypt is around 61000000 (N ational Information Centre, 1997). There is one psychiatric bed for every 6000 citizens; psychiatric hospital beds represent less than $10 \%$ of the total. These are largely concentrated in Cairo, bringing the ratio there to 1 bed per 2200 - the four public psychiatric hospitals in Cairo provide 5800 beds, and the remaining 1200 beds are distributed over the rest of Egypt (M inistry of $\mathrm{H}$ ealth, 1998). Psychiatric hospitals are currently experiencing difficulties in the provision of care, treatment and rehabilitation, as they have limited resources.

Egypt has one psychiatrist for every 130000 citizens, compared with one physician for every 500 . C linical psychologists total around 250 in the whole country, most of them also concentrated in the capital. The nurses working in the mental health field are general nurses - most have little or no training in psychiatric care. The more highly qualified nurses graduating in Egypt generally prefer to work abroad, often in the Gulf, where remuneration is much higher. There are many social w orkers practising in all psychiatric facilities, but they are mostly generic social workers, who have minimal graduate training in psychiatric social work. There is no training for occupational therapy in Egypt (0 kasha \& Karam, 1998).

\section{Training}

There are 13 medical schools in Egypt, each with a department of psychiatry (mainly providing out-patient services). Undergraduate training in psychiatry is often limited to a few days in the curriculum. There is a 4-year postgraduate psychiatric training programme in several of these schools. In 1948, Cairo U niversity started a diploma in psychological medicine and neurology.
Health expenditure

According to U nited $\mathrm{N}$ ations D evelopment Programme (UN DP), health expenditure, estimated as a percentage of gross domestic product (GDP), is 1\% in Egypt. This is far below the minimum expenditure of $5 \%$ of GDP recommended by the World $\mathrm{H}$ ealth $\mathrm{O}$ rganization, and may be compared with $13.7 \%$ in the USA (W orld H ealth O rganization, 1996). The M inistry of H ealth budget constitutes $1.9 \%$ of the national budget (Ministry of $\mathrm{H}$ ealth, 1998). The allocation of resources is directed tow ards endemic problems such as malnutrition, parasitic infestations (e.g. bilharzia), tuberculosis and maternal and child morbidity.

In a postal survey conducted by 0 kasha $\&$ Karam (1998) looking at psychiatric services in several Arab countries, there was a consensus among Arab psychiatrists about the need for:

o public mental health education

O an increase in the number of psychiatrists

o upgrading of the training and education of mental health professionals

o the development of preventive and community mental health care services.

\section{Research in Egypt}

Egypt is the most productive country in the Middle East in terms of the number of articles published per year over the past 30 years (176 articles). H ow ever, using another method of measuring research productivity - the number of articles per million of the population - Egypt w ould rank average to low (1.5 articles per million).

The region seems to lack a strategic, policy-oriented position on the research agenda. Furthermore, funding for academic research is limited and depends on the interests of the different financing organisations. 0 n the other hand, collaboration between different centres at the Arab, regional or international level will doubtless contribute to the development of research in the Arab world (O kasha \& Karam, 1998).

\section{Policies and future directions}

Egypt has a M ental H ealth Act dating back to 1944 and a documented health policy. Four years ago, the Ministry of $\mathrm{H}$ ealth adopted a new strategy, of centralisation of mental health services. In collaboration with several international agencies, this has facilitated the implementation of several projects to upgrade mental health services:

o a Finnish project on human resource development and the introduction of community-based services

o a UNDP project that concentrates on improving treatment services and rehabilitation for addiction

o a World $\mathrm{H}$ ealth $\mathrm{O}$ rganization project on the inclusion of psychiatry in primary care services, as well as support for community-based services.

\section{Mental health and culture}

As in the majority of developing countries, patients tend to present with somatic psychological symptoms. This
Around 1284 CE, the Sultan of Egypt, Al Mansour Kalawoon,

bequeathed one of his palaces in Cairo for the construction of a general hospital with a department of psychiatry.

Collaboration between different centres at the Arab, regional or international level will doubtless contribute to the development of research in the Arab world. 
presentation of mental ill health is reflected in the pattern of consultation. Patients tend to pass through different health care 'fitters' before they reach psychiatric clinics and hospitals. According to Goldberg \& Huxley (1992), almost two-thirds of patients with psychiatric symptoms attend only their general practitioner, and only $50 \%$ of those would be recognised as having a psychiatric disorder.

In this context, traditional and religious healers play a

Traditional and religious healers play a major role in primary psychiatric care in Egypt. They deal with minor neurotic, psychosomatic and transitory psychotic states using religious and group psychotherapies, suggestion and devices such as amulets and incantations. major role in primary psychiatric care in Egypt. They deal with minor neurotic, psychosomatic and transitory psychotic states using religious and group psychotherapies, suggestion and devices such as amulets and incantations (0 kasha, 1966). It was estimated that $60 \%$ of out-patients at the university clinic in C airo, which generally serves people from low socio-economic classes, have been to traditional healers before attending a psychiatrist (0 kasha $\&$ Hassan, 1968). In rural areas, community care is implemented without the need for health care workers. Egyptians, especially those living in the countryside, have a special tolerance of mental disorders and an ability to assimilate those with a chronic mental illness. For example, these patients, and those with mild or moderate learning disabilities, may cultivate crops along with, and under the supervision of, family members.

Thus, the real challenge for mental health professionals is the first filter, that is, patients acknowledging their mental health problems. H owever, this challenge cannot be met without a reorganisation of both the health-providing structures and the approach to medical education and training. The latter cannot be systemically tackled without the guidance of action-oriented and policy-oriented research.

\section{References}

Baasher, T. (1975) The Arab countries. In World History of Psychiatry (ed. J. G. Howells), pp. 547-578. N ew York: Bruner/Mazel.

Buergel (1975) Der Mufarrih an-nafs des Ibn Cladi Ba'albakk, ein Lehrbuch der Psychohygiene aus dem 7. Jahrhundert der $\mathrm{H}$ ijra. In Proceedings of the Sixth Congress of Arabic and Islamic Studies (ed. F. Rundgren), p. 204. Leiden.

Dols, M. W. (1992) In Majnun: The Madman in Medieval Islamic Society (ed. D. E. Immisch), p. 133. O xford: Clarendon Press.

Goldberg, D. P. \& Huxley, P. (1992) Common Mental Disorders: A Biosocial Model. London: Routledge.

Ministry of $\mathrm{H}$ ealth (1998) Statistics. Cairo: Ministry of $\mathrm{H}$ ealth.

$\mathrm{N}$ ational Information Centre (1997) Statistical Yearbook. Cairo: $\mathrm{N}$ ational Information Centre.

O kasha, A. (1966) A cultural psychiatric study of El-Zar cult in U.A.R. British Journal of Psychiatry, 112, 1217-1221.

0 kasha, A., Kamel, M. \& Hassan, A. H. (1968) Preliminary psychiatric observations in Egypt. British Journal of Psychiatry, 114, 949-955.

0 kasha, A. \& Karam, E. (1998) Mental health services and research in the Arab world. Acta Psychiatrica Scandinavica, 98, 406- 413.

O kasha, A., Seif El-Dawla, A., Khalil, A. H., et al (1993) Presentation of acute psychosis in an Egyptian sample: a transcultural comparison. Comprehensive Psychiatry, 34, 4-9.

World Health O rganization (1996) Recommendations for M ental Health Services. Geneva: WHO.

\section{Italian psychiatry - 25 years of change}

\section{Angelo Fioritti ${ }^{1}$, Mariano Bassi² and Giovanni de Girolamo ${ }^{3}$}

1Direttore Programma Salute Mentale e Dipendenze Patologiche, Azienda USL Rimini, via Coriano 38, 47900 Rimini, Italy, email afioritti@ausIrn.net; Elected President of the Italian Society for Addiction Psychiatry (Società Italiana Psichiatria delle Dipendenze - SIPD)

2Direttore Dipartimento Salute Mentale, Azienda USL Città di Bologna; Vice President of the Italian Society of Psychiatry (Società Italiana di Psichiatria - SIP)

${ }^{3}$ Dipartimento Salute Mentale, Azienda USL Città di Bologna; formerly responsible for the National Mental Health Project, National Institute of Health (Progetto Nazionale Salute Mentale, Istituto Superiore di Sanità), Rome

\begin{abstract}
talian psychiatry is probably more debated than known in the international arena. Law 180 of 1978, which introduced a radical community psychiatry system, has drawn worldwide attention and debate, with comments ranging from the enthusiastic to the frankly disparaging (Mosher, 1982; Jones et al, 1991). More recently, this interest was marked by a well-attended symposium 'Lessons Learned from Italian Reforms in Psychiatry' held at the 2003 annual meeting of the Royal College of Psychiatrists in Edinburgh.

$H$ istorical analyses of how the reform movement took momentum, produced a law and how it was enacted can be found elsewhere (Perris \& Kemali, 1985; Saraceno \& Tognoni, 1989; Mangen, 1989; Fioritti et al, 1997). In this
\end{abstract}

article we try to outline the general social context in Italy, its health and psychiatric services, their organisation, functioning and culture.

\section{Italian communities at a glance}

Italy is a country of 56995744 inhabitants (census of 21 0 ctober 2001) and its economy is the world's seventh largest in terms of gross domestic product (GDP) (World Bank, 2003). It has the world's fifth highest life expectancy at birth (76.9 years for men and 83.3 years for women) (World Health 0 rganization, 2003).

Administratively, the country is divided into 20 regions and 109 provinces. Because of its historical fragmentation until reunification in 1870 , striking social and economic 